\title{
A COMPARATIVE STUDY OF THE PERCEPTIONS OF
}

\author{
COMPETENCIES OF THE MEDICAL GRADUATES
}

\author{
AS ASSESSED BY THEMSELVES AND THEIR \\ SUPERVISORS IN A SRI LANKAN UNIVERSITY
}

\author{
BY \\ ROHANA BASIL MARASINGHE
}

Thesis submitted to the University of Sri Jayewardenepura for the awardd of the Dlexgree off MAraster offPhhlidossophy iim Mtectical Education on 2005. 


\section{DECLARATION BY THE CANDIDATE}

The work described in this thesis was carried out by me under the supervision of Professor M.T.M. Jiffry (Senior Professor, Head of the Department of Medical Education and Health Sciences, Faculty of Medical Sciences, University of Sri Jayewardenepura), Dr. Palitha Abeykoon (Senior Advisor, World Health Organisation, Colombo) and Dr. Chris Stephens (Director of Education, Division of Medical Education, School of Medicine, University of Southampton, United Kingdom) and a report on this thesis has not been submitted in whole or in part to any university or any other institution for another Degree/Diploma.

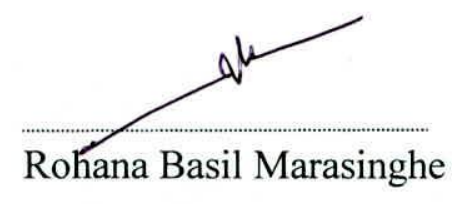

28/05/roob.

Date 


\section{DECLARATION OF THE SUPERVISORS}

We certify that the above statement made by the candidate is true and that this thesis is suitable for submission to the University for the purpose of evaluation.
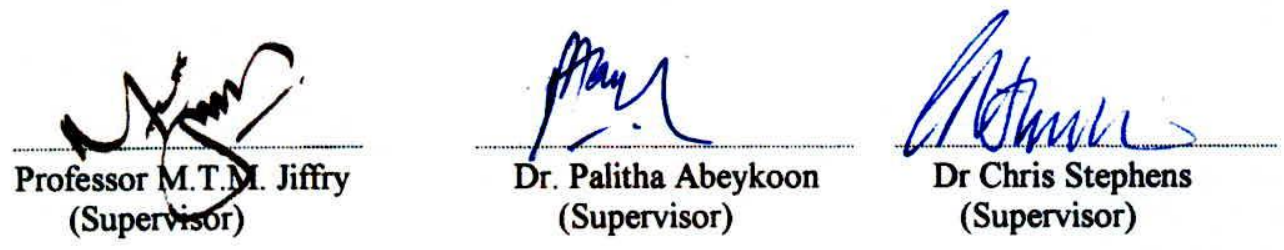


\section{TABLE OF CONTENTS}

\section{Page}

I. LIST OF TABLES vii

II. LIST OF FIGURES xi

III. ABBREVIATIONS xiii

IV. ACKNOWLEDGEMENTS XV

V. ABSTRACT xvii

$\begin{array}{ll}\text { 1. INTRODUCTION } & 01\end{array}$

$\begin{array}{ll}\text { 1.1. Background } & 01\end{array}$

1.1.1 General and higher education in Sri Lanka 01

1.1.2 Medical schools in Sri Lanka 02

1.1.3 Establishment and performance of the Faculty of Medical

Sciences of the University of Sri Jayewardenepura.(FMS/USJ) 03

1.1.4 Medical curriculum at FMS/USJ 03

1.1.5 Importance of evaluation of medical curriculum 05

1.1.6 Place of the measurement of competency in evaluating curricula 06

1.2. Context of the study 06

$\begin{array}{ll}\text { 1.3. Subject of study } & 07\end{array}$

$\begin{array}{ll}1.4 \text { Research questions } & 07\end{array}$

$\begin{array}{ll}\text { 1.5 Aims and objectives of the study } & 07\end{array}$

$\begin{array}{ll}\text { 1.5.1 Main objectives } & 08\end{array}$

$\begin{array}{ll}\text { 1.5.2 Specific objectives } & 08\end{array}$

1.6 Significance of the study 09

$\begin{array}{ll}\text { 1.7 Scope of the study } & 10\end{array}$ 
2. REVIEW OF LITERATURE II

2.1 The concept of curriculum and other related issues 11

2.1.1 The curriculum 11

$\begin{array}{ll}2.1 .2 \text { Medical curriculum } & 16\end{array}$

2.1.3 Evolutionary steps of medical curriculum and specific features of each step 17

2.2 The concept of curriculum evaluation and other related issues 23

2.2.1 Evaluation \& educational evaluation 23

2.3 Current trends on curriculum evaluation $\quad 30$

2.3.1 Current schools of thoughts $\quad 30$

2.3.1.i The school of outcome based education $\quad 30$

2.3.1.ii The school of standards based medical education $\quad 34$

2.3.2 Significant evaluation models . 35

2.3.2.i Traditional experimental design 36

2.3.2.ii Program logic model $\quad 37$

2.3.2.iii Educational interaction model $\quad 39$

2.3.2.iv Realistic evaluation $\quad 42$

2.3.2.v Kirkpatrick evaluation hierarchy 43

2.4 Concepts and issues related to developing a curriculum $\begin{array}{ll}\text { evaluation model } & 47\end{array}$

$\begin{array}{ll}\text { 2.4.1 Approaches to educational evaluation } & 47\end{array}$

2.4.1.i Student-oriented approach $\quad 47$

2.4.1.ii Programme-oriented approach 47

2.4.1.iii Institution-oriented approach $\quad 48$ 
2.4.1.iv Stakeholder-oriented approach

2.4.1.v Outcome-oriented approach

2.4.2 Indicators used in evaluation

2.4.2.i Structural evaluation measures

2.4.2.ii Outcome evaluation measures

2.4.2.iii Process evaluation measures

2.4.3 Evaluation techniques

2.4.3.i Quantitative techniques 57

2.4.3.ii Qualitative techniques

2.4.4 Evaluation tools

2.4.5 Important concepts regarding evaluation techniques

65

3. METHODOLOGY

3.1 Sample selection

3.1.1 Inclusion criteria $\quad 66$

$\begin{array}{lll}\text { 3.1.2 Exclusion criteria } & 67\end{array}$

3.1.3. Enrolment of research subjects 67

$\begin{array}{ll}\text { 3.2 Development of research tools } & 67\end{array}$

$\begin{array}{ll}\text { 3.2.1 Questionnaire development } & 68\end{array}$

$\begin{array}{lll}\text { 3.2.2 Semi structured interview guide } & 70\end{array}$

$\begin{array}{lll}\text { 3.2.3 Ethical clearance } & 71\end{array}$

$\begin{array}{ll}3.3 \text { Data collection } & 72\end{array}$

$\begin{array}{ll}\text { 3.4 Data analysis and interpretation } & 73\end{array}$

3.4.1 Analysis of survey data $\quad 73$

$\begin{array}{ll}\text { 3.4.2 Analysis of interview data } & 79\end{array}$ 
4. RESULTS 82

4.1 Sample distribution $\quad 82$

4.2 Achievement of Institutional Objectives 86

4.2.1 Area 1 Professional values, attitudes and behaviour $\quad 86$

4.2.2 Area 2 Scientific basis / foundation of medicine 89

4.2.3 Area 3 Clinical skills 92

4.2.4 Area 4 Communication skills 95

4.2.5 Area 5 Ethical and legal values associated with $\begin{array}{ll}\text { professional practice } & 101\end{array}$

4.2.6 Area 6 Population / community health and health system 104

4.2.7 Area 7 As a primary care physician

$\begin{array}{ll}\text { (Primary care medicine) } & 107\end{array}$

4.2.8 Area 8 Administrative aspect . 110

4.2.9 Area 9 Reflective practice 113

4.2.10 Area 10 Critical thinking and research 115

4.3 Competency of FMS/USJ graduates in managing common

$\begin{array}{ll}\text { health problems } & 121\end{array}$

$\begin{array}{ll}\text { 4.3.1 Common medical problems } & 123\end{array}$

$\begin{array}{ll}\text { 4.3.2 Common paediatric problems } & 127\end{array}$

$\begin{array}{ll}\text { 4.3.2 Common surgical problems } & 130\end{array}$

4.3.4 Common obstetric \& gynaecological problems 133

4.4 Overall competency for the health problem management

$\begin{array}{ll}\text { leaning adequacies } & 138\end{array}$ 


\section{DISCUSSION}

2.2 The achievements of Institutional Objectives (IOs)

of the FMS/USJ

2.2.1 Professional values, attitudes and behaviour

2.2.2 Scientific basis / foundation of medicine

2.2.3 Clinical skills

2.2.4 Communication skills

2.2.5 Ethical and legal values associated with professional practice

2.2.6 Population / community health and health system

2.2.7 As a primary care physician (Primary care medicine)

2.2.8 Administrative aspects

2.2.9 Reflective practice

2.2.10 Critical thinking and research

2.3 The level of competency of FMS/USJ graduates in managing common health problems of Sri Lanka

5.2.1 Common medical problems

5.2.2 Common paediatric problems

5.2.3 Common surgical problems

5.2.4 Common obstetric \& gynaecological problems 
6.1The extent to which graduates were capable of demonstrating the achievement of Institutional Objectives (IOs) of the FMS/USJ

6.2 The level of competency of FMS/USJ graduates in managing common health problems of Sri Lanka

6.2.1 Common medical problems

6.2.2 Common paediatric problems

6.2.3 Common surgical problems

6.2.4 Common obstetric and gynaecological problems

\subsection{Recommendations}

6.3.1 Institutional objectives

$\begin{array}{ll}\text { APPENDIX I } & \text { Publications \& communications from this thesis } \\ \text { APPENDIX II } & \text { Questionnaires (HO) and (Consultants) } \\ \text { APPENDIX III } & \text { Interview guides (HO) and (Consultants) } \\ \text { APPENDIX IV } & \text { Ethical application } \\ \text { APPENDIX V } & \text { Item score } \\ \text { APPENDIX VI } & \text { Non respondent rate for each item } \\ \text { APPENDIX VII } & \text { Institutional Objectives } \\ \text { APPENDIX VIII } & \text { Individual health problems and its frequency of occurrence } \\ \text { APPENDIX IX } & \text { Curriculum vitae }\end{array}$




\section{LIST OF TABLES}

Page

Table 2.1: $\quad$ Summary of some definitions denoted for educational evaluation in the context of its constructing components

Table 2.2: Three main areas and 12 learning outcomes -adapted from Harden et al., (1999)

Table 2.3: Nine major areas of international standards in basic undergraduate medical education -adapted from WFME report (2000)

Table 2.4: Kirkpatrick's 4 levels modified by Barr et al., (2003)

Table 2.5: Indicators used in evaluating educational innovations (Wilkes \& Bligh (1999)

Table 2.6: Comparison of Qualitative and quantitative research -adapted from Cook and Reichardt (1979)

Table 2.7: Commonly used evaluation tools in evaluation research -adapted from Wilkes \& Bligh (1999)

Table 2.8: Comparison of selected parameters of evaluation tools (adapted from Harvey (1998)

Table 2.9: $\quad$ Main features of interview types - adopted from Patton (1990) 64

Table 3.1: $\quad$ Maximum score ${ }^{(\mathrm{a})}$ for ten areas of IQs and relevant items for each area 
Table 3.2: An approximate guide to interpret the average score obtained for each area of IQS as subscales

Table 4.1: The number selected, responded and the reasons for not responding to questionnaire

Table 4.2 The study population of the responding HOs and consultants by province, district and category of the hospital

Table 4.3: Distribution of HOs and consultants in each discipline

Table 4.4: Duration of the internship of HOs and the experience of consultants

Table 4.5: The workload of HOs and supervisory work of consultants

Table 4.6 Responses pertaining to "Scienctific basis / foundation of medicine

Table 4.7: Responses pertaining to "Clinical Skills"

Table 4.8: Responses pertaining to "Communication skills

Table 4.9: Responses pertaining to "Ethical and legal values associated with professional practice"

Table 4.10: Responses pertaining to "Population / community health and health system"

Table 4.11: Responses pertaining to "Primary care medicine" 
Table 4.13: Responses pertaining to "Reflective practice"

Table 4.14: Responses pertaining to "Critical thinking and research"

Table 4.15: A summary of the analysis of responses pertaining to main ten areas of the IOs

Table 4.16a: Items with scores below average $(<2)$ values by two groups

Table 4.16b: Items with scored above average $(>2)$ values by two groups

Table 4.17: The Number selected, responded and the reasons for not responding for the interview

Table 4.18a: Responses for competency in managing common medical problems

Table 4.18b: Responses for adequacy of training in common medical problems

Table 4.19a: Responses for competency in managing common Paediatric problems

Table 4.19b: Responses for adequacy of training in common Paediatric problems

Table 4.20a: Responses for competency in managing common Surgical problems 
Table 4.20b: Responses for adequacy of learning in common Surgical problems

Table 4.21a: Responses for competency in managing common Obstetrics \& Gynaecological problems

Table 4.21b: Responses for adequacy of learning in common Obstetrics \& Gynaecological problems

Table 4.22a: Responses pertaining to the competency in managing common health problems

Table 4.22b: Responses pertaining to the adequacy of learning in common health problems 


\section{LIST OF FIGURES}

\section{Page}

Figure 1.1: The SPICES model - adapted by Harden (2000a)

Figure 2.1: The hidden curriculum -adapted from (Harden, 2001a)

Figure 2.2: Different curricular models evolved in medical education

Figure 2.3: Performance measurement and the performance management can be evaluated at operational and strategic levelsadapted from Kaplan and Norton (1990)

Figure 2.4: Three-circle model for outcome-based education (adapted from Harden et al., (1999)

Figure 2.5: Three-circle model for classifying learning outcomes (adapted from Harden et al., (1999)

Figure 2.6: Traditional experimental design

Figure 2.7: Programme logic model -adapted from Cooksy, et al., (2001)

Figure 2.8: Educational interaction model (interaction between educational influences and individual abilities)-adapted from Fischbein (1986) 40

Figure 2.9: Schematic diagram to illustrate the realistic evaluation as a cyclical process operating in an open system

Figure 2.10: Kirkpatrick's hierarchy of levels of evaluation and modified version by Barr et al., (2000) 
Figure 2.11: Schematic illustration showing reliability and validity

Figure 4.1: Bar chart to illustrate responses on "Professional values, attitudes and behaviour"

Figure 4.2: Bar chart to illustrate responses on "Scientific basis / foundation of medicine".

Figure 4.3: Bar chart to illustrate responses on "Clinical skills"

Figure 4.4: Bar chart to illustrate responses on "Communication skills"

Figure 4.5: $\quad$ Bar chart to illustrate responses on "Ethical and legal values associated with professional practice"

Figure 4.6: Bar chart to illustrate responses on "Population / community health and health system"

Figure 4.7: Bar chart to illustrate responses on "As a primary care physician (Primary care medicine)"

Figure 4.8: Bar chart to illustrate responses on "Administrative aspect"

Figure 4.9: Bar chart to illustrate responses on "Reflective practice"

Figure 4.10: Bar chart to illustrate responses on "Critical thinking sand research" 


\begin{tabular}{|c|c|}
\hline & ABBREVIATIONS \\
\hline ACGME & Accreditation Council for Graduate Medical Education \\
\hline CAL & Computer-Assisted Learning \\
\hline CHPs & Common Health Problems \\
\hline CIPP & Context-Inputs-Processes-Products \\
\hline CNAA & Council for National Academic Award \\
\hline CNS & Central Nervous System \\
\hline CSTH & Colombo South Teaching Hospital \\
\hline CVA & Cerebro Vascular Accidents \\
\hline CVS & Cardio Vascular System \\
\hline DREEM & Dundee Ready Education Environment Measure \\
\hline FGS/USJ & Faculty of Graduate Studies, University of Sri Jayewardenepura \\
\hline FMS/USJ & Faculty of Medical Sciences, University of Sri Jayewardenepura \\
\hline GCE - O/L & General Certificate of Education - Ordinary Level \\
\hline $\mathrm{GCE}(\mathrm{A} / \mathrm{L})$ & General Certificate of Education - Advanced Level \\
\hline GDM & Gestational Diabetes Mellitus \\
\hline GIT & Gastro Intestinal System \\
\hline GMC & General Medical Council \\
\hline GNP & Gross National Product \\
\hline GP & General Practitioners \\
\hline GUT & Genito Urinary System \\
\hline $\mathrm{HO}$ & House Officer \\
\hline IOs & Institutional Objectives \\
\hline IRQUE & Improving Relevance and Quality of Undergraduate Education \\
\hline $\mathrm{L} / \mathrm{T}$ & Learning and Teaching \\
\hline
\end{tabular}




\begin{tabular}{|c|c|}
\hline MBBS & Bachelor of Medicine and Bachelor of Surgery \\
\hline $\mathrm{MCQ}$ & Multiple Choice Questions \\
\hline $\mathrm{MOH}$ & Ministry of Health \\
\hline NHSL & National Hospital of Sri Lanka \\
\hline PBL & Problem Based Learning \\
\hline $\mathrm{PIH}$ & Pregnancy Induced Hypertension \\
\hline $\mathrm{PPH}$ & Post Partum Haemorrhage \\
\hline PROM & Preterm Rupture of Membrane \\
\hline PVD & Periperal Vascular Diseases \\
\hline QA & Quality Assurance \\
\hline SAARC & South Asian Association for Regional Corporation \\
\hline SBS & Subject Benchmark Statements \\
\hline $\mathrm{SD}$ & Standard Deviation \\
\hline SDMCG & Scottish Deans' Medical Curriculum Group \\
\hline SEQ & Structured Essay Questions \\
\hline SJP & Sri Jayewardenepura General Hospital \\
\hline SLMC & Sri Lanka Medical Council \\
\hline SPICES & Student-centred, Problem based, Integrated, Community-based, \\
\hline TB & Tuberculosis \\
\hline TH & Teaching Hospital \\
\hline TQM & Total Quality Management \\
\hline UGC & University Grant Commission \\
\hline UV & Utero Vaginal \\
\hline WFME & World Federation on Medical Education \\
\hline
\end{tabular}




\section{ACKNOWLEDGEMENTS}

I wish to thank all those who contributed in diverse ways to the work involving my study:

in particular, I would like to express my sincere thanks and heartfelt gratitude to my three supervisors; especially to my internal supervisor, Senior Professor M. T. M. Jiffry; for the fine inspiration concerning every new idea, for the guidance whenever it was needed, for the constructive criticism which was readily forthcoming and providing opportunities for enhanced training;

to Dr. Palitha Abeykoon for helping me to focus the study purposefully and facilitating the unhindered progress in my study.

Dr Chris Stephens, for the unstinted guidance in enhancing and elevating the quality of the work.

My sincere gratitude to Professor Sirimali Fernando for the encouragement extended throughout my study.

I wish to thank Dr David Silvium and Dr. Joanna Murray for their invaluable comments which enabled me to refine the methodology in qualitative methods and to Mr. D. Jayasinghe for his help in statistics and reappraising the quantitative methods of the study.

It is my obligation to extend my gratitude to Director General of Health Service, Dr. Kahada Liyanagamage and to Dr. Stanley de Silva, Director Education \& Training Unit for granting permission to collect data in the hospitals; and my heartfelt thanks goes to all the Directors/MS of the hospitals and their staff who helped me in many ways to collect data for the study. 
My warmest thanks goes to all the consultants and House Officers for devoting their time and providing their frank opinion in this study.

I am specially thankful to the staff of the Department of Medical Education and Health Sciences who helped me in many ways; to Miss Sujatha Seneviratne, to Dr. P.E.K.B. Ranatunge, Dr. M.D.A.Rodrigo, Dr. A.M.Rizvi, Dr. W.A.A. Abeywardene, Dr. U.L.M. Fahmy, Dr. M.M.M.Farzan, Dr. T.Athukorala, Mr. MK Munasinghe, Mr. B.J. Ramanayaka, Mr. Manjula Bandara and Mr. Liyanage.

I am really thankful to Mr. Daya Samaranayaka, visiting lecturer in English at the English Language Teaching Unit of the University of Sri Jayewardenepura for his commitment in proof reading and the preparation of the manuscript.

My heartfelt gratitude goes to the senior staff members and the colleagues who helped me in various stages of the study.

I am forever thankful to my mother and sister who helped me in many ways.

I DEDICATE THIS THESIS TO THE STUDENTS OF THE FACULTY OF MEDICAL SCIENCES 


\author{
A COMPARATIVE STUDY OF THE PERCEPTIONS OF \\ COMPETENCIES OF THE MEDICAL GRADUATES AS \\ ASSESSED BY THEMSELVES AND THEIR SUPERVISORS \\ IN A SRI LANKAN UNIVERSITY
}

ROHANA BASIL MARASINGHE

\begin{abstract}
The aim of the study was to evaluate the medical curriculum implemented at the Faculty of Medical Sciences of the University of Sri Jayewardenepura (FMS/USJ) through the performance of medical graduates. Two objectives were formulated to assess,(1) the extent to which graduates were capable of demonstrating the achievement of Institutional Objectives (IOs) of the FMS/USJ, and (2) the level of competency of FMS/USJ graduates in managing common health problems of Sri Lanka.
\end{abstract}

Two comparable questionnaires were administered to intern House officers (HOs) of 95/96 batch and to their immediate supervisors (consultants) in order to obtaining the perception of competencies of the medical graduates needed to achieve Institutional Objectives (IOs) of the FMS/USJ. The quantitative responses obtained by HOs and their consultants were compared to calculate the statistically significant differences. Qualitative data obtained by the interview was analysed to recognise the rational explanations and elaborations in subsequent triangulation of data. 
Similarly, HOs and their consultants were interviewed to assess the level of competency of FMS/USJ graduates in managing common health problems in Sri Lanka. Perception of the present competencies and learning adequacies at the undergraduate period were obtained to identify strong and weak areas of the curriculum. Thematic analysis was performed to identify and clarify issues emerged pertaining to the improvement of medical curriculum.

Results, overall revealed that the average perception of the achievement of IOs of FMS/USJ is satisfactory, although self-rating by HOs $56.1 \%(112.1 / 200)$ were higher than that of the consultants $49.4 \%(99.8 / 200)$. Out of the ten categories identified, the IOs related to the category of "Professional values, attitudes and behaviour" obtained the mean highest score both by HOs $62.5 \%$ (2.5/4) and consultants $60 \%(2.4 / 4)$. The HOs $42.5 \%(1.7 / 4)$ and consultants $37.5 \%$ (1.5/4) secured the least for the category of "Critical thinking and research".

Common health problems perceived by HOs and consultants were considered separately in four internship disciplines (i.e. Medicine, Paediatrics, Surgery and Obstetrics \& Gynaecology). Mean score for each area was more than six, in a ten-point scale. Similar to the IOs, the self-perception by HOs rating was higher than that of perception of the consultants. In general, present competencies of HOs in 'managing each health problem' was higher than that of the 'learning adequacies' during the undergraduate period and, the interview disclosed that it could mainly be attributed to the practical experience gained at the internship. Furthermore, the interview in-depth revealed the specific areas to be improved in the curriculum. 